\title{
Corrosion Resistance of a Steel Under an Oxidizing Atmosphere in a Fluid Catalytic Cracking Regenerator
}

\author{
Ieda Caminha ${ }^{\mathrm{a}}$, Chaoliu Zeng ${ }^{\mathrm{b}}$, Marcelo Piza Paes ${ }^{\mathrm{c}}$ \\ Maurício Jesus Monteiro ${ }^{\mathrm{d}}$, Fernando Rizzo ${ }^{\mathrm{d}}$ * \\ anstituto Nacional de Tecnologia, Laboratório de Metalografia e de Dureza \\ Av. Venezuela, 82, sala 626, 20081-310 Rio de Janeiro, Brazil \\ ${ }^{\mathrm{b}}$ Institute of Corrosion and Protection of Metals, State Key Laboratory for Corrosion and \\ Protection, The Chinese Academy of Science, 110015 Shenyang, China \\ 'PETROBRÁS/CENPES/SUPEP/DIPLOT/SEMEC, Cidade Universitária \\ Quadra 7, Ilha do Fundão, 21949-900 Rio de Janeiro, Brazil \\ ${ }^{\mathrm{d}}$ Pontifícia Universidade Católica do Rio de Janeiro,Departamento de Ciências dos \\ Materiais e Metalurgia, Rua Marquês de São Vicente, 225, 22 453-900 Rio de Janeiro, \\ Brazil
}

Received: September 2, 2002; Revised: September 4, 2002

In the present work, the corrosion resistance of an ASTM A 387 G11 steel was evaluated under two conditions: an oxidizing atmosphere in a fluid catalytic cracking regenerator of a petroleum processing unit and a simulated atmosphere in the laboratory, at temperatures of $650{ }^{\circ} \mathrm{C}$ and $700{ }^{\circ} \mathrm{C}$. The characterization of the phases present in the oxidized layer was carried out by X-ray diffraction (XRD), optical microscopy (OM) and scanning electron microscopy (SEM) with Xray energy dispersive analysis (EDS). Severe corrosion was observed after exposure to both the real and simulated conditions, with formation of several iron oxides $\left(\mathrm{Fe}_{2} \mathrm{O}_{3}, \mathrm{Fe}_{3} \mathrm{O}_{4}\right.$ and $\left.\mathrm{FeO}\right)$ in the product scale layer, as well as a slight inner oxidation and sulfidation of chromium in the substrate. Internal nitridation of the silicon and the manganese was observed only in the real condition, probably related to the long-term exposure inside the regenerator.

Keywords: corrosion resistance, low alloy steel, oxidant atmosphere, regenerator, petroleum processing unit

\section{Introduction}

Corrosion of materials may represent a heavy burden for industry in general, especially for the petroleum industry where the oil and gas compositions are responsible for reducing the service life of component materials of equipment due to severe corrosion attack and, consequently, to considerable expenses related to the maintenance and replacement of parts in a processing unit ${ }^{1-4}$. Production shutdown of a petroleum-processing unit can result in a loss of up to 80,000 distilled barrels in a single day.

In order to mitigate corrosion problems, two approaches are usually employed: the selection of corrosion resistant materials, which may increase the cost of equipment, or the application of a coating to a cheap but less corrosion resistance material. In recent years, several studies have been done in the field of coating protection and development of new

*e-mail: rizzo@dcmm.puc-rio.br

Presented at the International Symposium on High Temperature Corrosion in Energy Related Systems, Angra dos Reis - RJ, September 2002. alloys, aiming to minimize or eliminate corrosion on the metallic structure of critical parts. In the petroleum industry, thermally sprayed aluminum coatings have been successfully used for the protection of offshore and marine structures, due to its good corrosion resistance and consequent increase in the service life of metallic parts and equipments ${ }^{5}$.

In the present study, the corrosion resistance of an ASTM A 387 G11 low alloy steel was evaluated. This steel is widely employed in the manufacture of pressure vessels designed for elevated temperature service. Coupon samples were exposed to the oxidizing atmosphere in the regenerator region of a fluid catalytic cracking unit (FCCU) of an oil refinery and to a simulated condition in laboratory.

This study is relevant not only for the petroleum industry but also to those involving high temperature corrosion, 
such as thermal generation plants, because the understanding of the corrosion mechanisms at elevated temperature will allow for the optimization of the alloy and coating compositions used in such systems.

\section{Experimental}

Two experimental procedures were used: degradation of specimens in service and degradation of specimens in the laboratory, simulating the real conditions of service. In both cases, the corrosion resistance of an ASTM A 387

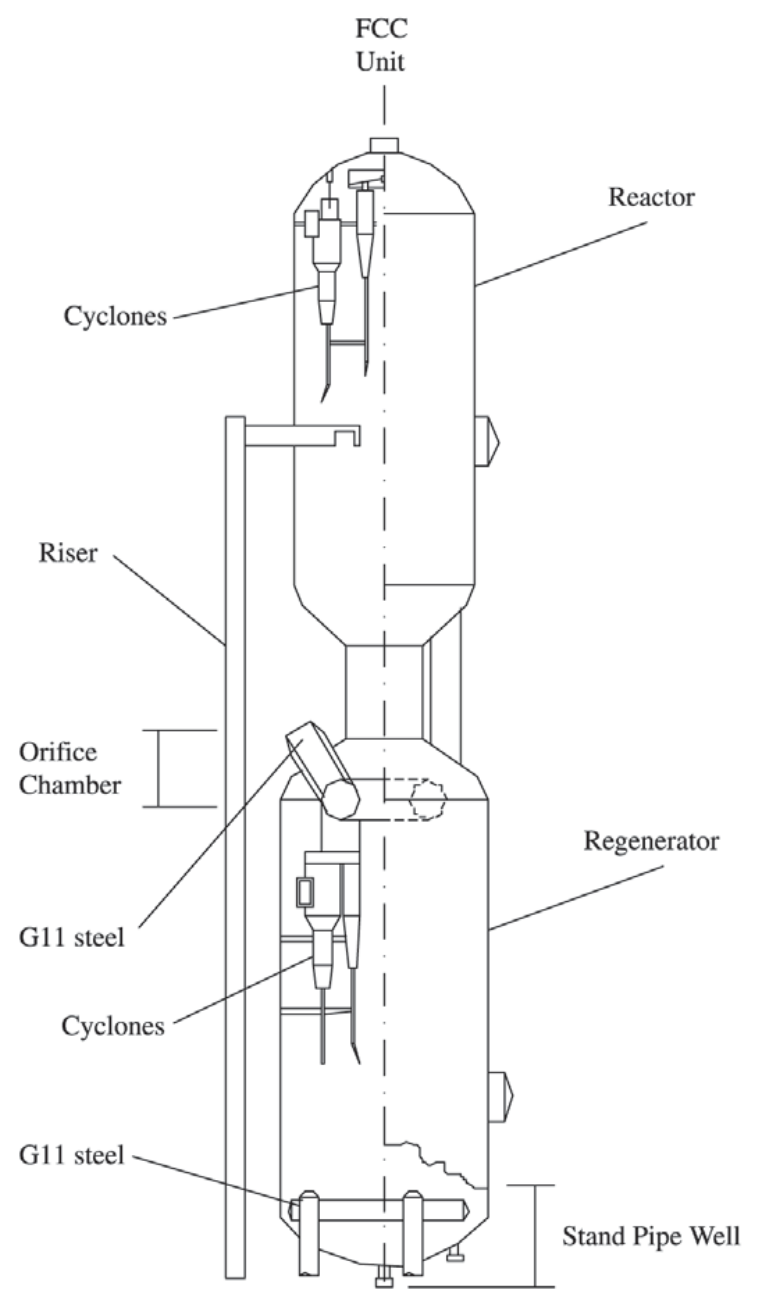

Figure 1. Schematic drawing of the FCC unit, indicating the local inside the regenerator where the G11 steel samples were fixed.
Grade 11 low alloy steel was evaluated, for which the nominal composition is presented in Table 1 .

For the degradation of specimens in service, designated "real condition", the samples were fixed inside the regenerator of a fluid catalytic cracking unit, more specifically in the stand pipe well and orifice chamber regions, under an oxidant atmosphere provided by the burning of the coke adhered to the catalyst. A schematic of the FCCU and the place where the samples were fixed is shown in Fig. 1.The samples were subjected to a temperature of around $650{ }^{\circ} \mathrm{C}$ in the stand pipe well and $700{ }^{\circ} \mathrm{C}$ in the orifice chamber regions for two and a half years, which is the usual time of a campaign in a petroleum processing unit.

In the second procedure the service atmosphere was simulated in the laboratory and was designated "simulated condition". A gas mixture with the composition $\mathrm{N}_{2}-2 \% \mathrm{O}_{2}$ $3 \% \mathrm{SO}_{2}-10 \% \mathrm{CO}_{2}$ (vol\%.) was used in order to simulate the atmosphere inside the regenerator. The resulting atmosphere was oxidizing, with the oxygen potential calculated to be $1.42 \times 10^{-2} \mathrm{~atm}$, the sulfur potential $6.79 \times 10^{-34} \mathrm{~atm}$ and the carbon activity virtually zero. In this condition, the samples were hung in a quartz tube inside a vertical furnace that was coupled to a temperature controller (PID). The variation in temperature was smaller than $0.5^{\circ}$. The flux of gas mixture was introduced in the quartz tube minutes before the furnace started heating. The sample was placed inside the fur-

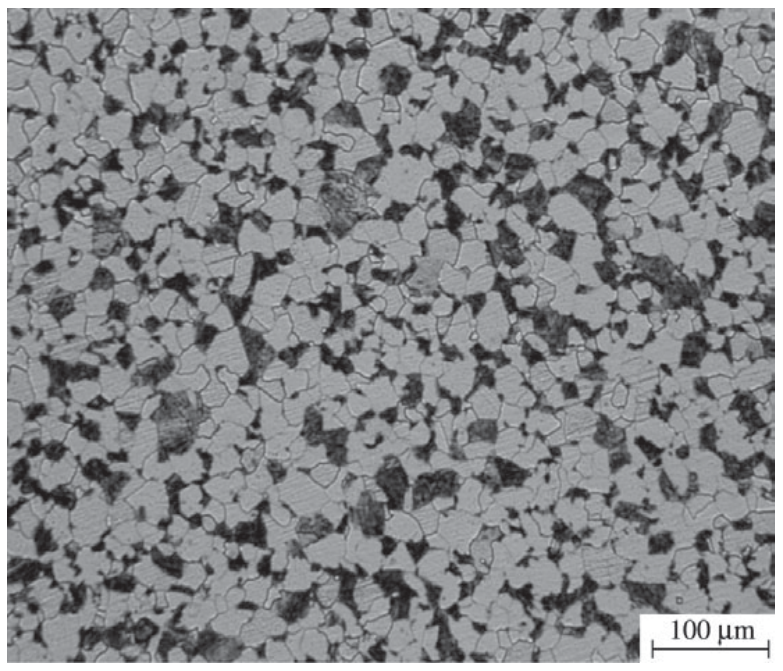

Figure 2. Micrography of the G11 steel sample before degradation. Etching: Nital 2\%.

Table 1. Nominal composition of ASTM A 387 G11 low alloy steel (wt.\%).

\begin{tabular}{ccccccc}
\hline$\% \mathrm{C}$ & $\% \mathrm{Mn}$ & $\% \mathrm{P}$ & $\% \mathrm{~S}$ & $\% \mathrm{Si}$ & $\% \mathrm{Cr}$ & $\% \mathrm{Mo}$ \\
\hline $0.05-0.17$ & $0.40-0.65$ & 0.0035 max. & $0.0035 \mathrm{max}$. & $0.50-0.80$ & $1.00-1.50$ & $0.45-0.65$ \\
\hline
\end{tabular}




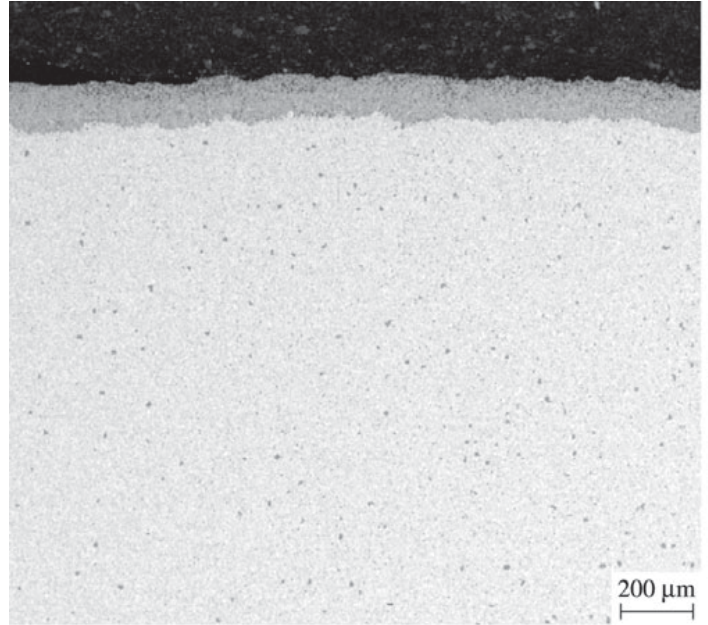

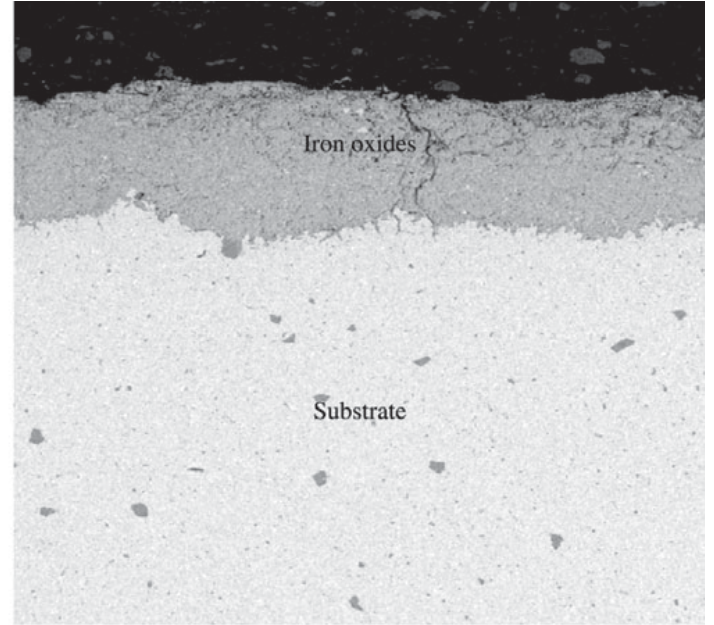

b)

Figure 3. SEM cross-section of the G11 steel sample subjected to the real condition at $650{ }^{\circ} \mathrm{C}$, with different magnifications. a) General view of the corroded layer and substrate; b) Expanded view of the corroded layer/substrate interface, showing in details the fissure in the corroded layer and the presence of precipitates in the substrate.

nace after the temperature of interest was reached. Sample cooling occurred inside the furnace after it had been turned off. The samples were subjected to a test temperature of $700{ }^{\circ} \mathrm{C}$ during $70 \mathrm{~h}$ of treatment.

After removing the samples from the regenerator (real condition) and the furnace (simulated condition), cross sections were cut and cold mounted for conventional metallographic preparation. The corroded surfaces were analyzed by X-ray diffraction (XRD), optical microscopy $(\mathrm{OM})$ and scanning electron microscopy (SEM) with X-ray energy dispersive analysis (EDS).

\section{Results and Discussion}

\section{G11 steel before degradation}

The original microstructure of the ASTM A 387 G11 before the corrosion degradation is presented in Fig. 2. It is constituted by ferrite and pearlite, with a fairly homogeneous grain size.

\section{G11 steel subjected to the real condition}

Severe corrosion was observed for both samples exposed to the oxidizing atmosphere inside the regenerator at the temperatures of $650{ }^{\circ} \mathrm{C}$ and $700{ }^{\circ} \mathrm{C}$. The formation of several iron oxides such as $\mathrm{Fe}_{2} \mathrm{O}_{3}, \mathrm{Fe}_{3} \mathrm{O}_{4}$ and $\mathrm{FeO}$, as well as a slight internal oxidation and sulfidation of the chromium and the iron in the substrate near the corroded layer/substrate interface were observed. A significant internal nitridation of the silicon and the manganese was also observed for both

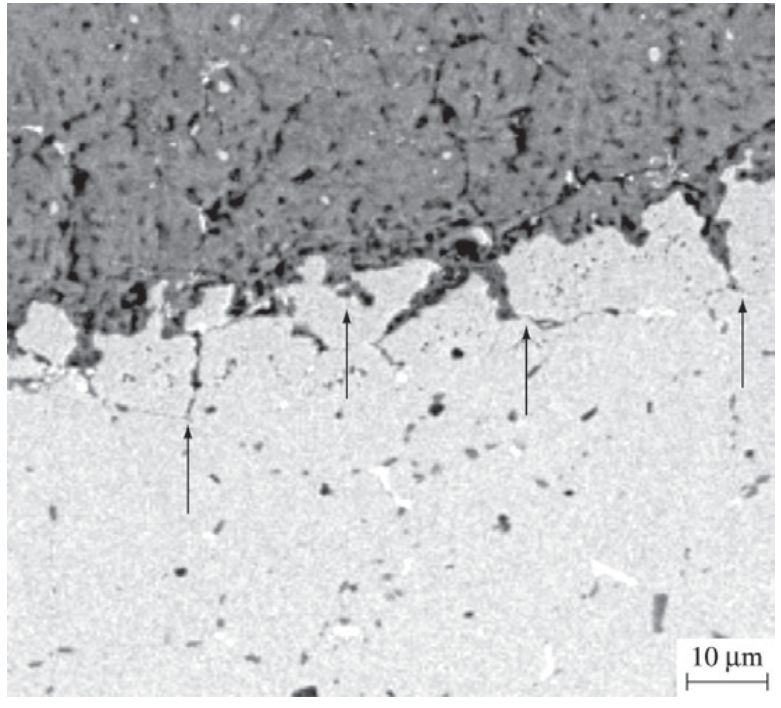

Figure 4. SEM micrograph of the corroded layer/substrate interface, showing the internal oxidation and sulfidation of the G11 steel sample subjected to the real condition at $650{ }^{\circ} \mathrm{C}$.

samples.

Figure 3 shows the morphology in cross-section of the G11 steel sample subjected to the real condition inside the regenerator, in the standpipe well region at $650{ }^{\circ} \mathrm{C}$.

The iron oxides present in the corrosion layer were confirmed by X-ray diffraction and are in accordance with the 
Fe-O phase diagram for the temperature studied. The corroded layer was very homogeneous (Fig. 3a), with a thickness around $100 \mu \mathrm{m}$. The fissure present accross the layer, extending from the surface to the corroded layer/substrate interface (Fig. 3b), may have formed during the cooling or metallographic preparation. This thickness value is very low if one considers the long time of sample exposure $(21 / 2$ years). However, the original thickness of the corroded layer might be larger. It is possible that during the campaign time of the processing unit, the corroded layer detached due to

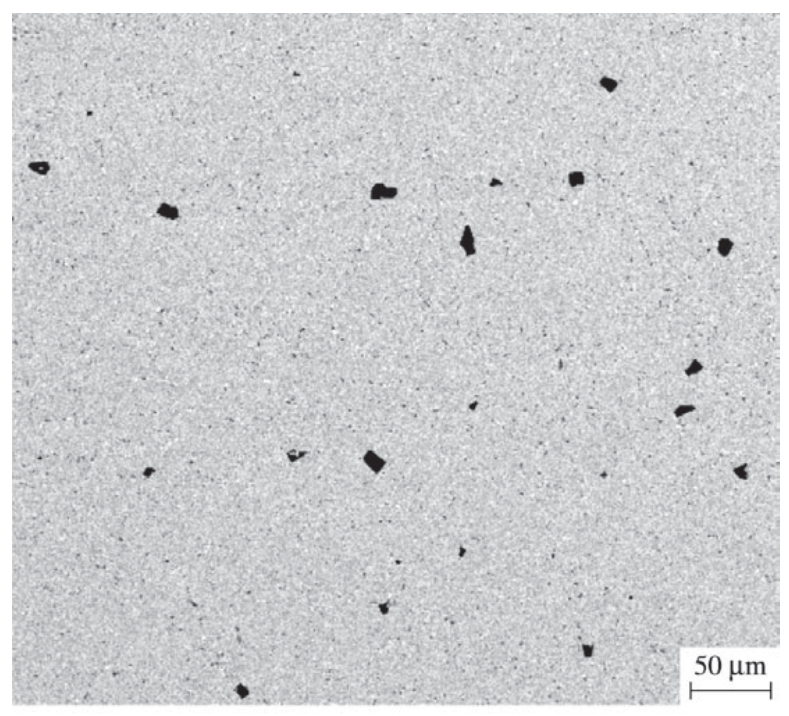

a)

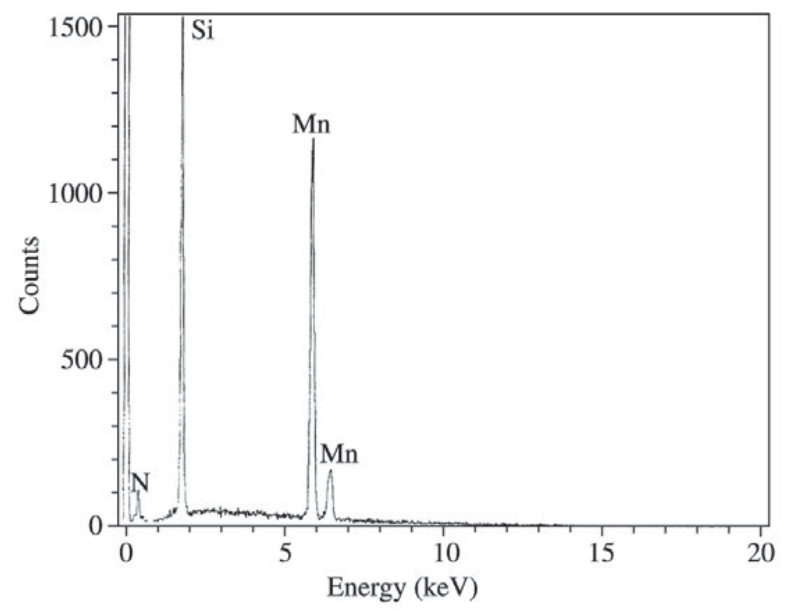

b)

Figure 5. Detail of the internal precipitation of the G11 steel sample at $650{ }^{\circ} \mathrm{C}$ in the real condition. a) SEM micrography illustrating the morphology of the precipitates; b) EDS spectrum of the precipitates. the intense wear present in the standpipe well region.

Figure 4 shows, at higher magnification, the corroded layer/substrate interface of the G11 steel in the real condition at $650{ }^{\circ} \mathrm{C}$.

The X-ray energy dispersive analysis -EDS confirmed the presence of oxygen, sulfur, chromium and iron, suggesting a slight internal oxidation and sulfidation of chromium and iron next to the interface. The porosity present in the corroded layer allowed quick oxygen and sulfur diffusion into the alloy, promoting the formation of iron and chro-

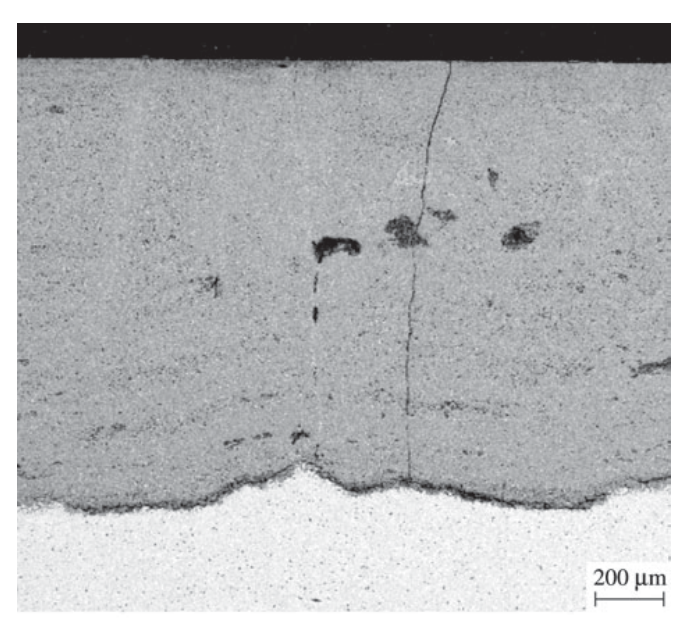

a)

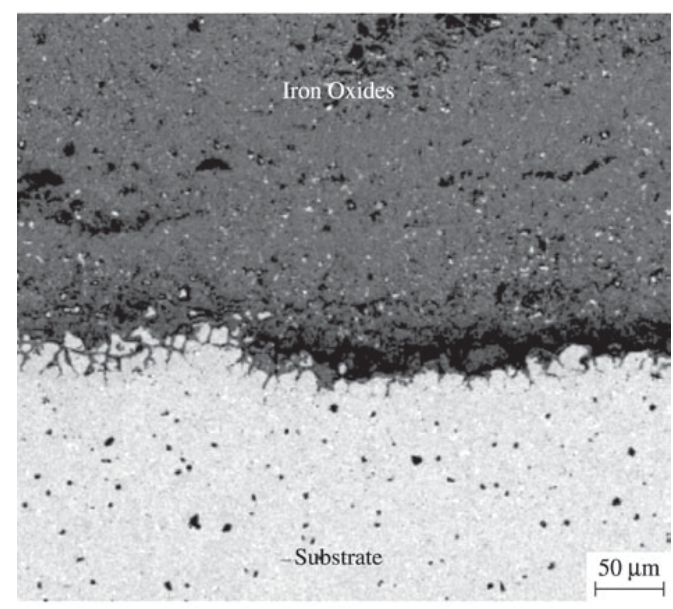

b)

Figure 6. SEM cross-section of the G11 steel sample subjected to the real condition at $650{ }^{\circ} \mathrm{C}$, with different magnifications. a) General view of the sample, showing in detail the fissure in the corroded layer; b) Expanded view, showing the corroded layer/ substrate interface and in detail the internal oxidation and sulfidation of the chromium and the iron. 
mium oxides and sulfides beneath the layer. In those internal regions, the oxygen activity becomes very low while sulfur activity becomes relatively high, leading to the formation of chromium and iron sulfides ${ }^{6-11}$.

Figure 5 shows the internal precipitation found in the G11 steel subjected to the real condition at $650{ }^{\circ} \mathrm{C}$. There was significant internal precipitation (Fig. 5a) throughout the entire substrate. The morphology of the precipitates was irregular both in size and geometry. An EDS spectrum (Fig. 5b) confirmed the presence of nitrogen, silicon and manganese suggesting an internal nitridation of the silicon and the manganese present in the alloy. The long time of exposure in the real service conditions ( 2.5 years), in which the temperature could reach $1000-1100{ }^{\circ} \mathrm{C}$ due to the burning of abnormal amount of coke in the catalyst surface, allowed nitrogen diffusion into the alloy and the reaction with less noble metals (Mn, Si), leading to the formation of manganese and silicon nitride ${ }^{12-13}$. In this case, the oxygen activity becomes very low (around $10^{-28}$ atm) while nitrogen activity becomes relatively high (around $10^{-3} \mathrm{~atm}$ ), leading to the formation of silicon and manganese nitrides $\left(\mathrm{Si}_{3} \mathrm{~N}_{4}\right.$ and $\mathrm{Mn}_{4} \mathrm{~N}$ ), according to phase stability diagrams for $\mathrm{Si}$ $\mathrm{Mn}-\mathrm{O}$ and $\mathrm{Si}-\mathrm{Mn}-\mathrm{N}$ systems ${ }^{14}$.

The G11 steel sample subjected to the real condition at $700{ }^{\circ} \mathrm{C}$ showed a similar corrosion behavior to that at $650{ }^{\circ} \mathrm{C}$. This can be seen in the Fig. 6 and 7. However, the thickness of the corroded layer, approximately $1000 \mu \mathrm{m}$, is compatible with the long time of exposure during the campaign of the processing unit (2.5 years).

Significant internal nitridation of the silicon and the manganese was also observed, with the long time of exposure in the real condition undoubtedly being responsible for the intense precipitation. The amount of precipitates in the G11 steel subjected to the higher temperature $\left(700{ }^{\circ} \mathrm{C}\right)$ is larger when compared to the sample exposed to the lower temperature $\left(650{ }^{\circ} \mathrm{C}\right)$, indicating the occurrence of higher nucleation rate which is a contradiction with the theory. This apparent contradiction can be explained because the sample subjected to the higher temperature was fixed in the orifice chamber region (Fig. 1), where the temperature changes during the abnormal FCCU operation conditions were not so significant when compared to the sample fixed in the stand pipe well region, where the temperature could reach $1000-1100{ }^{\circ} \mathrm{C}$. Another feature that could contribute to increase the amount of internal precipitates is the higher solubility of nitrogen in the alloy at $700{ }^{\circ} \mathrm{C}, 1685.4 \mathrm{ppm} v s$. $1335.8 \mathrm{ppm}$ at $650{ }^{\circ} \mathrm{C}$.

\section{G11 Steel subjected to the simulated condition}

Similar to the G11 steel samples exposed to the real condition at $650{ }^{\circ} \mathrm{C}$ and $700{ }^{\circ} \mathrm{C}$, severe corrosion as well as a slight internal oxidation and sulfidation of the chromium and the iron near the corroded layer/substrate interface was observed in the sample subjected to the simulated condition at $700{ }^{\circ} \mathrm{C}$. However, the corroded layer was not homogeneous when compared to those resulting from the real condition, presenting two distinct layers: the smoother external one, constituted predominantly by $\mathrm{Fe}_{3} \mathrm{O}_{4}$ and the inner layer with great porosity, where the EDS analysis detected primarily sulfur and chromium, leading probably to the formation of $\mathrm{Cr}_{2} \mathrm{~S}_{3}$. The corroded layer was detached from the substrate along their interface.

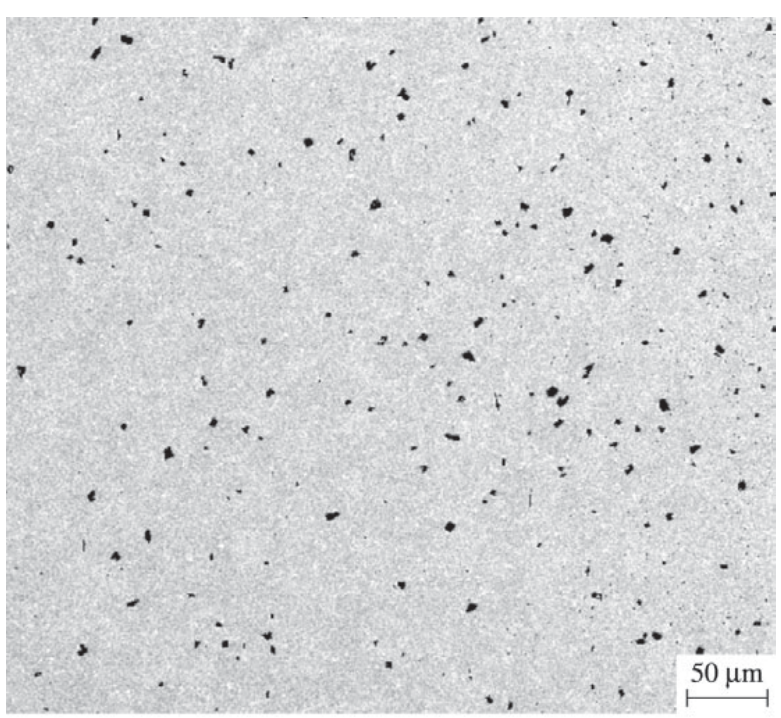

a)

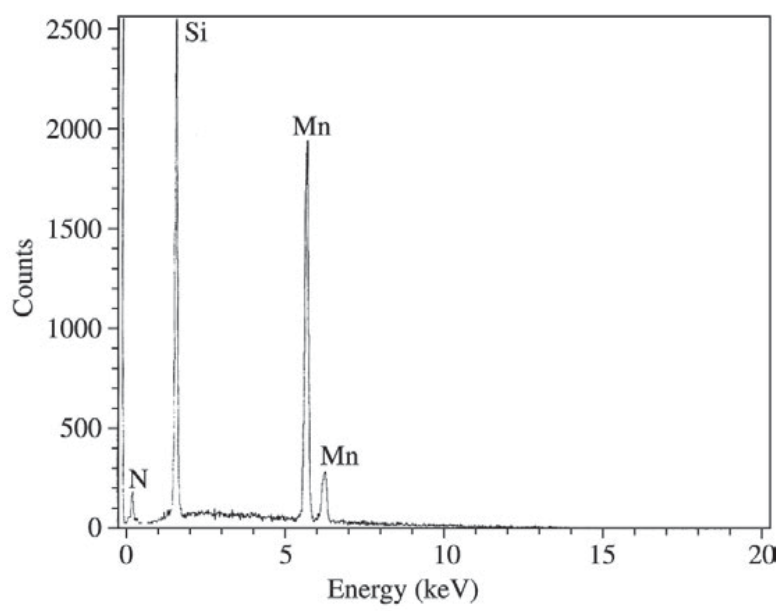

b)

Figure 7. Detail of the internal precipitation of the G11 steel sample at $700{ }^{\circ} \mathrm{C}$ in the real condition. a) SEM micrography illustrating the morphology of the precipitates; b) EDS spectrum of the precipitates. 


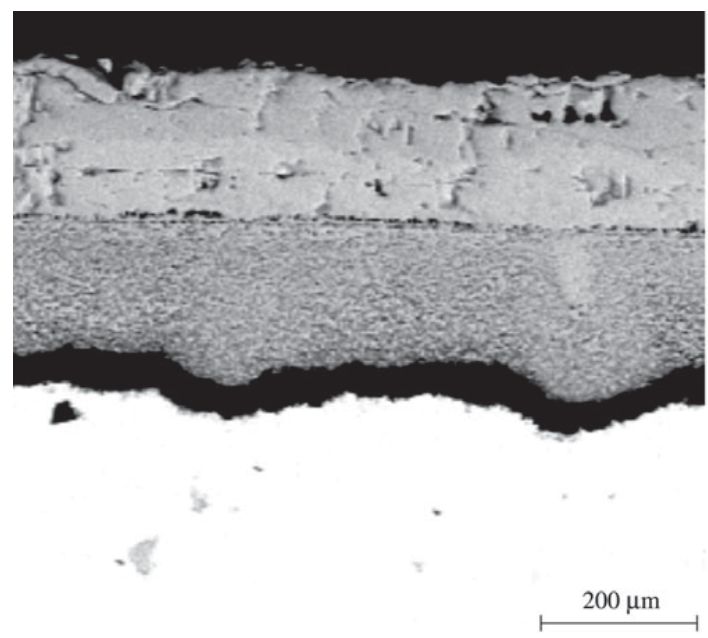

a)

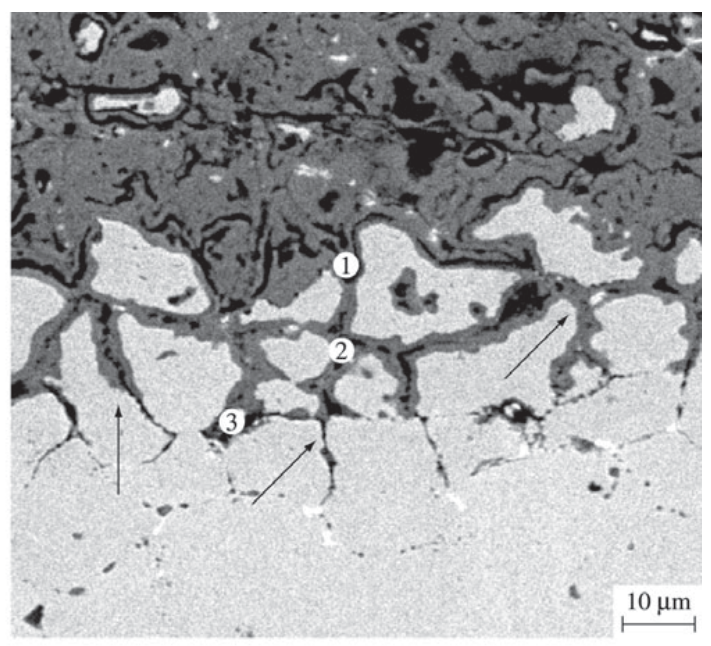

b)

Figure 8. SEM cross-section of the G11 steel sample subjected to the simulated condition at $700{ }^{\circ} \mathrm{C}$. a) General view of the corroded layer and substrate showing in detail the detachment of the layer from the substrate; b) Detail of the corroded layer/substrate interface, showing the internal oxidation and sulfidation.

Figure 8a shows the general view of the corroded layer and substrate. One can observe clearly the presence of two distinct layers and the detachment of the corroded layer from the substrate. In Fig. 8b, the internal oxidation and sulfidation of the substrate are indicated by arrows.

No sign of internal nitridation of the silicon and the manganese was observed in the G11 steel sample subjected to the simulated condition at $700{ }^{\circ} \mathrm{C}$ during $70 \mathrm{~h}$. This may be an indication that the internal precipitation is related to the long time of exposure inside the regenerator (2.5 years) in the real service condition.

\section{Conclusions}

Exposure of the G11 steel samples to both real and simulated conditions allowed for easy oxygen and sulfur ingress into the substrate, promoting the formation of a corroded layer containing Fe oxides. The occurrence of internal sulfidation and oxidation next to the corroded layer/substrate interface was also observed.

There was significant internal nitridation of the silicon and the manganese observed in the G11 steel samples subjected to the real condition, which is probably related to the long time of exposure inside the regenerator of the fluid catalytic cracking unit.

The oxidizing atmosphere in both the real and simulated conditions, allowed for the rather rapid penetration of oxygen, sulfur, and nitrogen into the alloy, leading to internal oxidation, sulfidation, and nitridation of the G11 steel, suggesting that this steel cannot be employed in the atmosphere studied.

\section{Acknowledgments}

The authors thank the Science and Technology Ministry of Brazil and FINEP for the financial support trough ÔMEGA project and USIMINAS for supplying the steel.

\section{References}

1. Charles, J.; Bonnefopis, B.; Dupoiron, F. Materials Science and Engineering, v. 87, p. 151-159, 1987.

2. May, V.E. Materials Performance, p. 18-22, 1985.

3. Walker, H.B. Hydrocarbon Processing, p. 80-84, 1984.

4. Agarwal, D.C.; Brill, U.; Heubner, U. The NACE Annual Conference, Paper n. 4511992.

5. Fischer, K.P.; Thomason, W.H.; Rosbrook, T.; Murali, J. The NACE Annual Conference, Paper n. 499, 1994.

6. Wood, G.C. Oxidation of Metals, v. 2, n.1, p. 11-56, 1970.

7. Kofstad, P. High Temperature Corrosion, Elsevier Applied Science, London \& New York, 1988.

8. Giggins, C.S.; Petit, F.S. Oxidation of Metals, v. 14, n. 5 , p. 363-413, 1980.

9. Young, D.J.; Watson, S. Oxidation of Metals, v. 44, n. 1/ 2, p. 239-263, 1995.

10. Caminha, I.; et all. Materials Science Forum, v. 369372, p. 655-662, 2001.

11. Rizzo, F.; et all., The NACE Annual Conference, Paper n. 1169, 2001.

12. Besters, D. Diffusion, American Society of Metals, Metals Park, OH, p. 209-240, 1973.

13. Leslie, W. Physical Metallurgy of Steels, McGraw-Hill, New York, p. 112, 1981.

14. Software HSC OUTOKUMPU. 